\title{
Electrocardiographic criteria of left atrial enlargement: Do they correlate with atrial size?
}

\author{
BRIAN PAHLOW, DO \\ FRANK CORBALLY, DO \\ ALAN GEISLER, DO \\ JACQUELINE CATER, PhD
}

In the past, M-mode echocardiography, the "gold standard" for determining left atrial dimension (LAD), has been used to examine the validity of the New York Heart Association criteria for left atrial enlargement (LAE). When the authors used two-dimensional echocardiography to determine LAD in 91 patients, they found no significant correlation between any of these criteria, either alone or together, and actual LAE. They propose that if the diagnosis of LAE is made using these criteria alone, that it be qualified at all times with the word "possible."

The diagnosis of left atrial enlargement (LAE) is commonly inferred by electrocardiographic criteria. In fact, the New York

From the department of medicine/cardiology, University of Medicine and Dentisty of New Jersey-School of Osteopathic Medicine, Stratford, NJ. Dr Pahlow, a senior fellow in cardiology at the time this paper was written, is presently a practicing cardiologist in Salem, NJ. Dr Corbally is associate professor and Dr Geisler is assistant professor of clinical medicine. Dr Cater is a biostatistician, department of academic computing services, UMDNJ-SOM.

Reprint requests to Frank Corbally, DO, $301 \mathrm{~S}$ Central Plaza and Laurel Rd, Suite 3100 , Stratford, NJ 08084-1504.

Heart Association (NYHA) has proposed electrocardiographic criteria for the diagnosis of LAE, despite the fact that a number of papers have shown little or no correlation between these criteria and echocardiographic evidence of LAE. The study reported here attempts to confirm the validity of the NYHA criteria.

To date, all but one of the published reports ${ }^{1}$ concerning this issue have used the M-mode echocardiographic measurements to determine left atrial dimension (LAD). Two-dimensional echocardiography, however, ensures a more accurate and consistent means of measuring; it avoids overestimation or underestimation of the size of the left atrium that can result from tangentially imaging the atrium via standard M-mode methods. In our study, we used only two-dimensional echocardiograhic images and made all measurements directly from them.

In addition, we examined only the three most commonly used criteria for LAE. It is our opinion that although the $\mathrm{P}$ wave axis has been established as a fourth criterion in the diagnosis of LAE in common practice, it is not used routinely.

\section{Patients and methods}

The patient population for this study was derived by two methods. First, we reviewed all electrocardiograms (ECGs) of patients with a diagnosis of LAE over a 6-month period dur- 


\begin{tabular}{|c|c|c|c|c|c|}
\hline \multicolumn{6}{|c|}{$\begin{array}{c}\text { Table } 2 \\
\text { Correlation of New York Heart Association Criteria for Left Atrial } \\
\text { Enlargement (LAE) With Echocardiographic Measurement of } \\
\text { Left Atrial Dimension (LAD) }\end{array}$} \\
\hline \multirow[b]{2}{*}{$\begin{array}{l}\text { ECG criterion } \\
\text { of LAE }\end{array}$} & \multirow[b]{2}{*}{$\begin{array}{l}\text { No. of } \\
\text { patients }\end{array}$} & \multirow[b]{2}{*}{$\begin{array}{l}\text { Correlation } \\
\text { with LAD* }\end{array}$} & \multicolumn{3}{|c|}{ Diagnosis } \\
\hline & & & $\begin{array}{c}\text { Correct } \\
(\%)\end{array}$ & $\begin{array}{l}\text { False- } \\
\text { positive } \\
(\%)\end{array}$ & $\begin{array}{l}\text { False- } \\
\text { negative } \\
(\%)\end{array}$ \\
\hline $\begin{array}{l}\text { P wave duration } \\
\text { lead II }\end{array}$ & 91 & $\begin{array}{l}.131 \\
(.216)\end{array}$ & 51.5 & 8.8 & 41.7 \\
\hline $\begin{array}{l}\text { Terminal P wave } \\
\text { depth in lead } V_{1}\end{array}$ & 91 & $\begin{array}{l}.142 \\
(.179)\end{array}$ & 20.9 & 75.8 & 3.3 \\
\hline $\begin{array}{l}\text { Terminal P wave } \\
\text { width in lead } V_{1}\end{array}$ & 91 & $\begin{array}{l}.133 \\
(.208)\end{array}$ & 40.6 & 49.5 & 9.9 \\
\hline $\begin{array}{l}\text { Combination of all } \\
\text { three criteria }\end{array}$ & 91 & $\cdots$ & 20.9 & 78.0 & 1.1 \\
\hline
\end{tabular}

ing the year 1987. Seventy-seven ECGs met the following criteria for LAE, as established by the NYHA ${ }^{2}$ :

- A wide, notched $\mathrm{P}$ wave $(>0.11$ second in duration) in lead II;

- A biphasic $P$ wave in $V_{1}$ with a terminal negative component $>0.04$ second wide, and $>$ $1 \mathrm{~mm}$ deep.

Of these 77 ECGs, we excluded 28 either because there was no echocardiogram available or the one that was available posed technical difficulty in making accurate measurement of the left atrium.

Next, we randomly reviewed the two-dimensional echocardiographic reports of 62 patients during 1987, looking for only those with an enlarged left atrium. Feigenbaum ${ }^{3}$ reports the range of normal LAD to be from $19 \mathrm{~mm}$ to 40 $\mathrm{mm}$. Therefore, we defined LAE as any dimension $>40 \mathrm{~mm}$. We then reviewed a 12 -lead ECG obtained within 1 year of the two-dimensional echocardiograph for each of the 62 patients with regard to each of the three NYHA criteria. Only 42 patients among this population had ECGs available for review or were not in atrial fibrillation. We excluded the remaining 20 patients from the study.

A total of 91 patients remained in these two groups to form the study population (Table 1).

The echocardiograms were made with the patients in the left lateral decubitus position by use of a Hewlett Packard system with a 2.5- $\mathrm{mHz}$ transducer. The left atrial dimension was measured directly from the two-dimensional image of the parasternal long axis view, following established criteria ${ }^{4}$

\section{Statistical analysis}

Initial review of the data revealed a degree of bias attributable to the manner in which the study population was derived. In each case, one major variable, ECG criteria, or LAD was always abnormal; therefore, the population was not truly random and no absolute statement can be made with regard to specificity because there are no true-negative diagnoses included in the study population. Nevertheless, we observed trends and roughly assessed the sensitivity of these criteria for predicting LAE.

Statistical analysis was based on a chisquare test and the Pearson correlation coefficient. We analyzed each of the NYHA criteria individually for a possible correlation with LAD. A $P$ value of $<.05$ indicated statistical significance. Chi-square analysis was used to evaluate each of the criteria individually and as a group for the ability to predict a correct diagnosis, a false-positive diagnosis, and a false-negative diagnosis. We also assessed the sensitivity of these three criteria for diagnosing LAE.

\section{Results}

As Table 2 shows, there was no statistically significant correlation found between any of 


\begin{tabular}{|c|c|c|c|c|c|c|c|c|c|}
\hline \multirow[b]{3}{*}{$\begin{array}{l}\text { Record } \\
\text { No. }\end{array}$} & \multicolumn{8}{|c|}{$\begin{array}{l}\text { Table 1 } \\
\text { Electrocardiographic and Two-Dimensional Echocardiographic } \\
\text { Findings in Study Population }(\mathrm{N}=91)\end{array}$} & \multirow{3}{*}{$\begin{array}{c}\text { Left atrial } \\
\text { dimension on } \\
\text { two-dimensional } \\
\text { echocardiography, } \\
\mathrm{mm}\end{array}$} \\
\hline & \multirow[b]{2}{*}{$\begin{array}{l}\text { Lead } \\
\text { II, } s\end{array}$} & \multirow[b]{2}{*}{$\begin{array}{l}\text { Lead } V_{1} \\
\text { width, s }\end{array}$} & \multirow[b]{2}{*}{$\begin{array}{c}\text { Lead } V_{1} \\
\text { depth, mm }\end{array}$} & \multirow{2}{*}{$\begin{array}{c}\text { Left atrial } \\
\text { dimension on } \\
\text { two-dimensional } \\
\text { echocardiography, } \\
\text { mm }\end{array}$} & \multirow[b]{2}{*}{$\begin{array}{l}\text { Record } \\
\text { No. }\end{array}$} & \multirow[b]{2}{*}{$\begin{array}{l}\text { Lead } \\
\text { II, } \mathrm{s}\end{array}$} & \multirow[b]{2}{*}{$\begin{array}{l}\text { Lead } V_{1} \\
\text { width, s }\end{array}$} & \multirow[b]{2}{*}{$\begin{array}{c}\text { Lead } V_{1} \\
\text { depth, mm }\end{array}$} & \\
\hline & & & & & & & & & \\
\hline 1 & 0.12 & 0.06 & 1.80 & 30 & 47 & 0.12 & 0.04 & 1.00 & 56 \\
\hline 2 & 0.12 & 0.06 & 1.00 & 45 & 48 & 0.11 & 0.08 & 1.50 & 34 \\
\hline 3 & 0.14 & 0.06 & 1.00 & 57 & 49 & 0.12 & 0.04 & 1.00 & 34 \\
\hline 4 & 0.12 & 0.08 & 1.00 & 45 & 50 & 0.11 & 0.04 & 0.50 & 50 \\
\hline 5 & 0.14 & 0.04 & 1.00 & 43 & 51 & 0.12 & 0.04 & 1.00 & 48 \\
\hline 6 & 0.14 & 0.06 & 1.00 & 42 & 52 & 0.12 & 0.08 & 1.00 & 45 \\
\hline 7 & 0.12 & 0.08 & 1.00 & 42 & 53 & 0.11 & 0.04 & 0.50 & 48 \\
\hline 8 & 0.12 & 0.08 & 1.00 & 37 & 54 & 0.12 & 0.04 & 0.50 & 54 \\
\hline 9 & 0.11 & 0.06 & 1.00 & 41 & 55 & 0.08 & 0.08 & 1.00 & 45 \\
\hline 10 & 0.14 & 0.08 & 1.00 & 47 & 56 & 0.08 & 0.04 & 0.20 & 46 \\
\hline 11 & 0.12 & 0.06 & 1.00 & 44 & 57 & 0.11 & 0.04 & 0.50 & 43 \\
\hline 12 & 0.12 & 0.04 & 1.00 & 38 & 58 & 0.08 & 0.00 & 0.00 & 46 \\
\hline 13 & 0.12 & 0.08 & 1.00 & 41 & 59 & 0.08 & 0.04 & 0.50 & 47 \\
\hline 14 & 0.12 & 0.04 & 1.00 & 46 & 60 & 0.14 & 0.04 & 1.00 & 49 \\
\hline 15 & 0.12 & 0.08 & 1.00 & 50 & 61 & 0.12 & 0.04 & 1.00 & 45 \\
\hline 16 & 0.11 & 0.04 & 2.00 & 37 & 62 & 0.08 & 0.00 & 0.00 & 45 \\
\hline 17 & 0.11 & 0.04 & 1.00 & 45 & 63 & 0.11 & 0.04 & 0.50 & 51 \\
\hline 18 & 0.12 & 0.08 & 1.00 & 56 & 64 & 0.12 & 0.06 & 1.20 & 45 \\
\hline 19 & 0.11 & 0.04 & 1.00 & 45 & 65 & 0.08 & 0.04 & 0.75 & 49 \\
\hline 20 & 0.12 & 0.04 & 1.00 & 54 & 66 & 0.16 & 0.06 & 1.00 & 62 \\
\hline 21 & 0.11 & 0.04 & 1.00 & 53 & 67 & 0.12 & 0.04 & 1.00 & 47 \\
\hline 22 & 0.11 & 0.08 & 1.00 & 35 & 68 & 0.11 & 0.00 & 0.00 & 46 \\
\hline 23 & 0.11 & 0.08 & 1.00 & 36 & 69 & 0.16 & 0.00 & 0.00 & 47 \\
\hline 24 & 0.12 & 0.06 & 1.00 & 50 & 70 & 0.11 & 0.04 & 0.50 & 46 \\
\hline 25 & 0.12 & 0.06 & 1.00 & 40 & 71 & 0.08 & 0.04 & 0.25 & 48 \\
\hline 26 & 0.11 & 0.04 & 1.00 & 50 & 72 & 0.14 & 0.06 & 1.00 & 56 \\
\hline 27 & 0.12 & 0.04 & 1.00 & 49 & 73 & 0.08 & 0.00 & 0.00 & 45 \\
\hline 28 & 0.11 & 0.08 & 1.50 & 41 & 74 & 0.12 & 0.04 & 0.50 & 50 \\
\hline 29 & 0.11 & 0.06 & 1.00 & 49 & 75 & 0.11 & 0.04 & 0.50 & 50 \\
\hline 30 & 0.11 & 0.04 & 1.00 & 39 & 76 & 0.08 & 0.04 & 0.50 & 45 \\
\hline 31 & 0.12 & 0.04 & 1.00 & 36 & 77 & 0.11 & 0.08 & 1.50 & 49 \\
\hline $\begin{array}{l}31 \\
32\end{array}$ & 0.11 & 0.04 & 1.00 & 36 & 78 & 0.11 & 0.08 & 0.50 & 41 \\
\hline 33 & 0.11 & 0.04 & 1.00 & 46 & 79 & 0.11 & 0.00 & 0.00 & 43 \\
\hline 34 & 0.12 & 0.08 & 2.00 & 47 & 80 & 0.06 & 0.00 & 0.00 & 48 \\
\hline 35 & 0.12 & 0.06 & 1.00 & 53 & 81 & 0.11 & 0.00 & 0.00 & 43 \\
\hline 36 & 0.12 & 0.04 & 1.00 & 47 & 82 & 0.11 & 0.04 & 1.00 & 49 \\
\hline 37 & 0.12 & 0.06 & 1.50 & 48 & 83 & 0.08 & 0.04 & 0.50 & 43 \\
\hline 38 & 0.12 & 0.06 & 1.00 & 38 & 84 & 0.12 & 0.08 & 1.00 & 47 \\
\hline 39 & 0.11 & 0.06 & 1.00 & 40 & 85 & 0.08 & 0.00 & 0.00 & 49 \\
\hline 40 & 0.12 & 0.06 & 1.50 & 45 & 86 & 0.08 & 0.04 & 0.25 & 46 \\
\hline 41 & 0.12 & 0.04 & 1.00 & 62 & 87 & 0.12 & 0.08 & 1.00 & 48 \\
\hline 42 & 0.11 & 0.06 & 1.00 & 51 & 88 & 0.11 & 0.04 & 1.00 & 46 \\
\hline 43 & 0.12 & 0.08 & 1.00 & 42 & 89 & 0.11 & 0.04 & 1.00 & 50 \\
\hline 44 & 0.12 & 0.06 & 1.00 & 35 & 90 & 0.12 & 0.02 & 0.50 & 53 \\
\hline 45 & 0.11 & 0.04 & 1.00 & 54 & 91 & 0.12 & 0.06 & 2.00 & 51 \\
\hline 46 & 0.12 & 0.08 & 1.00 & 51 & & & & & \\
\hline
\end{tabular}

the three ECG criteria and LAD at a $P$ value of $<.05$. Additionally, a large percentage of false-positive diagnoses (mean, 44.7\%) and an average of $31.3 \%$ incorrect diagnoses were elicited by use of these criteria, either alone or as a group.

By again subdividing our study population and looking only at those 42 patients who were enrolled on the basis of an enlarged left atrium, we were able to assess the sensitivity of these ECG criteria as a group for predicting LAE. Only 15 out of 42 patients with LAD > $40 \mathrm{~mm}$ (range, $40-62 \mathrm{~mm}$ ) actually met all three NYHA criteria. Thus, the sensitivity of these criteria as a group for predicting LAE was only $35 \%$.

It is of interest to note, however, that despite all of these data showing poor correlation between these three criteria and LAD, when only those patients with LAD $>55 \mathrm{~mm}$ 
$(n=6)$ were reviewed, each met all three ECG criteria for LAE.

\section{Discussion}

From a review of the literature on LAE and its diagnosis by ECG criteria, it is apparent that other investigators have been skeptical of the validity of these criteria.

As early as 1958, Macruz and associates, ${ }^{5}$ dissatisfied with the lack of sensitivity and specificity of the available criteria, established the Macruz index, which is the ratio of the Pwave duration to the PR segment. This ratio was then added to the already existing criteria, with LAE being present when the ratio is $>1.6$.

However, several studies ${ }^{6,7}$ published soon thereafter showed this index to be disappointingly insensitive in diagnosing LAE and the ratio in patients with coronary artery disease to be unpredictable regardless of LAD. In 1966, Gooch and associates ${ }^{8}$ showed leftward P-wave axis to be $>95 \%$ specific for the presence of LAE and reaffirmed the usefulness of these criteria in the diagnosis of LAE. In the mid1970 s, a series of studies ${ }^{9,10}$ using M-mode echocardiography to confirm LAD showed a high degree of correlation between echocardiographic assessment of LAD and ECG criteria for LAE. Like our study, this series was not randomized or controlled; however, unlike our study, each of these studies included a large percentage of patients with valvular heart disease (50\% to $90 \%)$.

Then, in a 1978 landmark study, Josephson and associates ${ }^{11}$ attempted to uncover once and for all the mechanism of the ECG pattern of LAE. They correlated left atrial size and pressure as well as interatrial conduction with ECG criteria for LAE by use of M-mode echocardiography, mean pulmonary capillary wedge pressure, and activation time from the $\mathrm{P}$ wave to the coronary sinus.

Only prolongation of interatrial conduction time was consistently related to the ECG pattern of LAE.

Furthermore, when they analyzed the etiologic type of heart disease, an enlarged left atrium correlated with electrocardiographic LAE only in patients with rheumatic mitral valve disease (eight of nine).
Our findings are in agreement with those of the more recent study by Roelandt and Medina ${ }^{1}$ in that no correlation was found between the ECG criteria for LAE and LAD measured by two-dimensional echocardiographic images. If ECG criteria alone were to be relied on to make a diagnosis of LAE, it is clear that between $60 \%$ and $75 \%$ of the cases would be missed. It is possible that these criteria are better predictors of LAE in a population of patients with valvular heart disease as opposed to the general population. Years ago when valvular heart disease was far more prevalent than today, left atrial dimensions were probably of a much greater proportion; and, as our data would indicate, at LADs of $>55 \mathrm{~mm}$, these criteria were extremely sensitive $(95 \%)$.

Because there is a 50-50 chance of an incorrect diagnosis using these criteria for LAE, we believe that at the present time, it would be better to leave the diagnosis to the echocardiographer. Or, if one insists on using these criteria as a diagnostic tool, one should always qualify the diagnosis as possible LAE.

1. Roelandt I, Medina E: Left atrial enlargement: An electrocardiographic misnomer? An electrocardiographic echocardiographic study. Eur Heart $J$ 1986;7:115-117.

2. Criteria Committee of the New York Heart Association: Nomenclature and Criteria for Diagnosis of Diseases of the Heart and Great Vessels, ed 7. Boston, Little Brown \& Co, 1973, pp 91-93.

3. Feigenbaum H: Echocardiography, ed 4. Philadelphia, Lea \& Febiger, 1986, p 464.

4. Weyman A: Cross-Sectional Echocardiography. Philadelphia, Lea \& Febiger, 1982, p 194.

5. Macruz R, Perloff J, Case R: A method for the electrocardiographic recognition of atrial enlargement. Circulation 1958;17:882-889.

6. Kahn M, Scheuer J, Wachtel F, et al: An evaluation of the ratio of P-wave duration to P-R segment in the diagnosis of atrial enlargement. Am Heart $J$ 1960;60:23-32.

7. Human G, Snyman H: The value of the Macruz index in the diagnosis of atrial enlargement. Circulation 1963;27:935-938.

8. Gooch A, Calatayud J, Gorman P, et al: Leftward shift of the terminal P forces in the ECG associated with left atrial enlargement. Am Heart $J$ 1966;71:727-733.

9. Chirife R, Feitosa G, Frankl W: Electrocardiographic detection of left atrial enlargement: Correlation of $P$ wave with left atrial dimension by echocardiography. Br Heart $J$ 1975;37:12811285.

10. Termini B, Lee Y: Echocardiographic and electrocardiographic criteria for diagnosing left atrial enlargement. South Med J 1975;68:161-165.

11. Josephson M, Kastor, Morganroth J: Electrocardiographic left atrial enlargement: Electrophysiologic, echocardiographic and hemodynamic correlates. Am $J$ Cardiol 1978;39:967-971. 